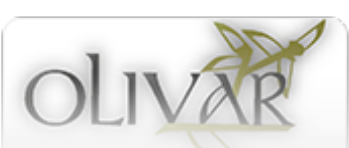

Olivar

ISSN: $1852-4478$

publicaciones@fahce.unlp.edu.ar

Universidad Nacional de La Plata

Argentina

\title{
Censura y creación literaria II. Entrevistas a Juan Marsé, Carlos Rojas, Mario Vargas Llosa y José María Vaz de Soto
}

Álvarez Villalobos, María; Suárez Toledano, Cristina

Censura y creación literaria II. Entrevistas a Juan Marsé, Carlos Rojas, Mario Vargas Llosa y José María Vaz de Soto

Olivar, vol. 19, núm. 30, 2019

Universidad Nacional de La Plata, Argentina

DOl: https://doi.org/10.24215/18524478e066

Esta obra está bajo una Licencia Creative Commons Atribución-NoComercial-Compartirlgual 4.0 Internacional. 


\title{
Censura y creación literaria II. Entrevistas a Juan Marsé, Carlos Rojas, Mario Vargas Llosa y José María Vaz de Soto
}

\author{
María Álvarez Villalobos \\ Universidad de Alcalá, España \\ Cristina Suárez Toledano \\ Universidad de Alcalá, España
}

DOI: https://doi.org/10.24215/18524478e 066

Con el objetivo de difundir el testimonio de quienes se vieron afectados de alguna manera por la censura editorial, publicamos la segunda entrega de una serie de entrevistas realizadas a algunos autores que escribieron sus primeras obras durante el régimen franquista: Juan Marsé, Carlos Rojas, Mario Vargas Llosa y José María Vaz de Soto. Las preguntas y respuestas que se muestran a continuación forman parte de un proyecto que comenzó en 2018, bajo la tutela del profesor Fernando Larraz en la Universidad de Alcalá, cuyo objetivo principal era conocer de primera mano cómo vivieron los escritores la censura, cuál fue su relación con ella y cómo afectó a sus obras. Si bien los expedientes de censura que contienen los informes redactados por los funcionarios de la Administración se encuentran a disposición pública en el Archivo General de la Administración, en Alcalá de Henares (Madrid), consideramos que el testimonio de estos autores puede constituir una fuente primaria relevante para futuros estudios de la censura, tanto desde el punto de vista de la historia literaria como de la historia cultural en un sentido más amplio.

Los cuatro cuestionarios que se presentan en esta entrega, ordenados alfabéticamente, son muy similares dado que todos fueron enviados por correo electrónico, partiendo de una misma base. Puesto que no se trata de una conversación directa con los autores, como lo fue en el caso de la entrega anterior, las respuestas son más breves que las de Antonio Ferres y Juan Mollá. Esto afecta también a la ausencia de preguntas relacionadas con las respuestas de los entrevistados. Contactamos por correo personalmente con Rojas y Vaz de Soto, pero en el caso de Marsé y Vargas Llosa fue la Agencia Literaria Carmen Balcells la que sirvió de intermediaria entre los escritores y nosotras. Estos autores empezaron a publicar sus novelas cuando aún estaba en vigor la primera Ley de Prensa franquista y continuaron haciéndolo durante la Ley de Prensa e Imprenta de 1966. El conjunto de sus respuestas contribuye a que los lectores se hagan una idea de cómo concebían los autores la creación literaria y de cómo enfrentaban el lápiz rojo de los censores. Destaca especialmente la represión que sufrieron los primeros títulos de Marsé y Vargas Llosa, todos ellos publicados por la editorial barcelonesa Seix Barral.

\section{Entrevista a Juan Marsé}

Juan Marsé (Barcelona, 1933) es un novelista que ha retratado a la perfección el ambiente de la ciudad de Barcelona a través de su obra literaria. Sus primeros libros se insertan en el marco del realismo social dominante en la novela española de mediados de los años cincuenta y que se prolongó hasta una década más tarde, como ejemplifican Encerrados con un solo juguete (1961) y Últimas tardes con Teresa (1966) ganadora del Premio Biblioteca Breve concedido por la editorial Seix Barral y ampliamente censurada por la administración franquista-, en las que el autor critica el modo de vida y las costumbres de los jóvenes de la burguesía catalana. A sus primeras obras siguieron otras de carácter renovador como Si te dicen que caí (1973), publicada directamente en México ante la imposibilidad de que viera la luz en España, El amante 
bilingüe (1990), El embrujo de Shanghai (1993) y Rabos de lagartija (2000). Como reconocimiento a su labor creadora, en 2008 resultó ganador del Premio Cervantes y sus últimas publicaciones son Noticias felices en aviones de papel (2014) y Esa puta tan distinguida (2016).

María Álvarez Villalobos y Cristina Suárez Toledano:Durante la redacción de sus obras, cuando tomaba una decisión sobre temática, de léxico..., ¿hasta qué punto tenía presente que los textos que estaba escribiendo serian sometidos a la inspección de la censura?

J.M.: En el momento de escribir solo tengo en cuenta problemas de estructura, lenguaje y ritmo narrativo. Es en la concepción del tema a tratar cuando preveía posibles dificultades con la censura -durante la dictadura franquista, no después- pero eso no hacía cambiar mis planes.

M.Á.V.y C.S.T.: ¿Cree que la publicación de Encerrados con un solo juguete, Esta cara de la luna y Últimas tardes con Teresa pudo verse favorecida o perjudicada por las relaciones de la editorial en cuestión con la administración censora? ¿Cree que ello afectaba de algún modo a su relación con los editores de la época?

J.M.: En absoluto.

Con Carlos Barral mantuve una larga relación de amistad y de trabajo, desde que nos conocimos en 1959 hasta su muerte. Fue mi primer editor y el más importante.

M.Á.V. y C.S.T.:Tras recibir un informe de denegación o de tachaduras para la publicación de algunas de sus obras, ¿qué camino a seguir le pareció más apropiado?

J.M.: Solo tuve problemas serios con dos novelas, Últimas tardes con Teresa y Si te dicen que caí. Ambas novelas recibieron del departamento de censura la notificación de NO AUTORIZA SU PUBLICACIÓN. Para la primera conseguí autorización después de entrevistarme en Madrid con el responsable de censura de aquel entonces, Carlos Robles Piquer. La autorizó con pequeños retoques sin importancia. La segunda novela, Si te dicen que caí, yo sabía que no pasaría censura y ni siquiera busqué la autorización. La presenté a un concurso internacional en México, ganó y fue publicada en ese país en 1973. En España no fue autorizada hasta 1976, después de la muerte de Franco, y se publicó sin ningún corte.

M.Á.V. y C.S.T.:En el caso de Últimas tardes con Teresa, ¿tuvo elección o la editorial tomó esa decisión por usted?

J.M.: Todas la decisiones que tenían que ver con la censura, las tomé de acuerdo con Carlos Barral, mi editor.

M.Á.V. y C.S.T.:¿Habría afrontado esa situación de la misma forma en la actualidad?

J.M.: Supongo que sí. No tengo motivos para pensar lo contrario. Afortunadamente hoy la literatura no está sujeta a la censura gubernamental.

M.Á.V. y C.S.T.: ¿En qué medida conserva una obra su valor literario si no se respeta la voluntad de quien la escribe? ¿En qué grado cree que la censura afectó al resultado de sus primeras novelas y a su difusión?

J.M.: Bueno, conserva todo su valor literario -si de verdad lo tiene- en su totalidad. En mis primeras novelas la censura no pudo hincar el diente. Fue a partir de Últimas tardes con Teresa que tuve problemas.

M.Á.V. y C.S.T.:Desde el final de la dictadura, ¿ha valorado la posibilidad de reeditar sus obras de forma integra, sin las supresiones o modificaciones de la censura? ¿Por qué?

J.M.: No. No veo la necesidad. Nunca tuve que suprimir nada importante, ni para la trama ni para el lenguaje.

M.Á.V. y C.S.T.:En relación con Si te dicen que caí, usted ha dicho que fue la primera novela que escribió sin autocensurarse. ¿Por quélo hizo?

J.M.: No dije exactamente eso. Dije que fue la primera que escribí sin pensar en la censura. Es decir, pensando en publicarla en España. Y se publicó en México, como he explicado antes. 


\section{Entrevista a Carlos Rojas}

Carlos Rojas (Barcelona, 1928) es un prolífico autor de novelas y ensayos. Doctor en Filosofía y Letras, Rojas ha sido profesor de Literatura Española en diferentes universidades de Estados Unidos. Muchas de sus novelas pueden adscribirse a una corriente metafísica y de marcado carácter fantástico en la que el autor se aleja del realismo social imperante a mediados de los años cincuenta y de los sesenta, época en la que comenzó su andadura en el mundo literario. A su primer título, De barro y esperanza (1957), han seguido más de una treintena de obras de las que pueden destacarse, entre otras, Las llaves del infierno (1962), Auto de fe (1968), reconocida con el Premio Nacional de Literatura, y El jardin de Atocha (1990). Sus numerosos ensayos abordan, en su mayoría, cuestiones relativas a personajes y hechos históricos de España, como puede verse en títulos como Azaña (1973), La Barcelona de Picasso (1981), Yo, Goya (1990) y Diez crisis del franquismo (2003), su última publicación.

María Álvarez Villalobos y Cristina Suárez Toledano:Durante la redacción de sus obras, cuando tomaba una decisión sobre temática, de léxico..., ¿hasta qué punto tenía presente que los textos que estaba escribiendo serían sometidos a la inspección de la censura?

Carlos Rojas: No tenía en cuenta la censura. Se escribe porque se tiene la voluntad de hacerlo. Cuento ahora con 89 años en las costillas y acabo de empezar mi última novela.

M.Á.V. y C.S.T.: ¿Cree que la publicación de sus primeras obras pudo verse favorecida o perjudicada por las relaciones de la editorial en cuestión con la administración censora?: Cree que ello afectaba de algún modo a su relación con los editores de la época?

C.R.: Es difícil contestarlo porque había un contubernio, parecido al de Múnich, entre editores, censores y escritores. Me parece que los censores aguardaban el cambio de régimen para seguir siéndolo con la democracia.

M.Á.V. y C.S.T.: Tras recibir un informe de denegación o de tachaduras para la publicación de alguna de sus obras, ¿qué camino a seguir le pareció más apropiado: sustituir o suprimir los pasajes tachados o tratar de publicarla de forma integra en el extranjero, con la consecuente pérdida de lectores españoles?

C.R.: En el extranjero la literatura española importaba muy poco, tirando a nada. Publicar allí era un privilegio reservado a Camilo y La familia de Pascual Duarte.

M.Á.V. y C.S.T.: ¿Tuvo elección o las editoriales tomaron esa decisión por usted?

C.R.: Nunca intentó una editorial tomar o alterar una de mis decisiones. Al menos que yo sepa.

M.Á.V. y C.S.T.:¿Habria afrontado esa situación de la misma forma en la actualidad?

C.R.: Como vine a decir con anterioridad, esta sería una ardua consideración porque nos aseguran que ahora todo ha cambiado.

M.Á.V. y C.S.T.:¿Le sorprendió que, pese a su carácter de fuerte crítica a la religión, se autorizara sin tachaduras Las llaves del infierno? ¿En quémedida la autocensura pudo afectar al contenido de la obra?

C.R.: Hoy me parece que la obra entera y verdadera pasó la censura; pero no lo recuerdo de cierto.

M.Á.V. y C.S.T.: Desde el final de la dictadura, ¿ha valorado la posibilidad de reeditar sus obras de forma integra, sin las supresiones o modificaciones de la censura, o de la autocensura? ¿Por qué?

C.R.: Como bien dice Rafael Borràs, el verdadero escritor siempre escribe la misma obra.

M.Á.V. y C.S.T.: ¿En qué medida conserva una obra su valor literario si no se respeta la voluntad de quien la escribe? ¿En qué grado cree que la censura afectó al resultado de sus primeras novelas y a su difusión?

C.R.: No lo he valorado porque si siempre se escribe la misma novela, paradójicamente el autor o la autora son siempre distintos y aquí precisaría Ortega puesto que ellos han vivido diferentes circunstancias. 


\section{Entrevista a Mario Vargas Llosa}

Mario Vargas Llosa (Arequipa, Perú, 1936) es un destacado escritor que se dio a conocer gracias a su novela La ciudad y los perros (1962), ganadora del Premio Biblioteca Breve otorgado por la editorial Seix Barral y publicada por primera vez en España, a pesar de las dificultades impuestas por la censura. De hecho, se considera esta publicación como uno de los hitos indispensables para el llamado "boom de la novela hispanoamericana", movimiento en el que Vargas Llosa comparte protagonismo con autores como Carlos Fuentes, Gabriel García Márquez y José Donoso, entre otros. De entre su obra novelística pueden resaltarse títulos como La casa verde (1966), Conversación en La Catedral (1969) y La fiesta del Chivo (2000). Además, ha publicado numerosos ensayos, trabajos de carácter periodístico y obras de teatro, así como varios volúmenes de cuentos. Recientemente ha publicado Tiempos recios (2019), la que es hasta la fecha su última novela. Fruto de su dilatada carrera literaria, Vargas Llosa ha recibido importantes galardones literarios como el Premio Cervantes (1994) y el Premio Nobel de Literatura (2010).

María Álvarez Villalobos y Cristina Suárez Toledano:Durante la redacción de sus primeras obras, cuando tomaba una decisión sobre temática, de léxico..., ¿hasta qué punto tenía presente que los textos que estaba escribiendo serian sometidos a la inspección de la censura española?

Mario Vargas Llosa: No, desde luego que no lo tenía presente. Escribí mis primeros cuentos en el Perú y creo que jamás me pasó por la cabeza la sospecha de que tendrían que pasar por un censor antes de publicarse. En esa época, los años 50, había en el Perú una dictadura muy severa, pero no se practicaba la censura de libros por la sencilla razón de que en el Perú prácticamente no se publicaban libros, sino se los importaba del extranjero.

M.Á.V. y C.S.T.:¿Cree que la publicación de sus primeras obras pudo verse favorecida o perjudicada por las relaciones de la editorial Seix Barral con la administración censora?

M.V.LL.: La censura siempre perjudica y jamás trae algo positivo a los libros. Coacta la imaginación de los que escriben y muchas veces los obliga a dar rodeos o a suprimir cosas adelantándose al escollo de la censura.

M.Á.V.y C.S.T.:¿Cómo fue su relación con los editores de la época, como Carlos Barral?

M.V.LL.: Mi relación con Carlos Barral fue magnífica. Era un enemigo declarado de la censura, como yo mismo, y dio una verdadera batalla de cerca de un año para conseguir que la censura admitiera mi primera novela, La ciudad y los perros. Incluso me llevó a almorzar con el jefe de la censura de esa época, el señor Robles Piquer, con el que tuvimos una larga discusión. Al final, la censura me obligó a hacer siete cortes de palabras, que Carlos Barral se atrevió a reponer en la segunda y demás ediciones de este libro.

M.Á.V. y C.S.T.: Tras recibir un informe de denegación o de tachaduras para la publicación de alguna de sus obras, ¿qué camino a seguir le pareció más apropiado: sustituir o suprimir los pasajes tachados o tratar de publicarla de forma integra fuera de España, con la consecuente pérdida de lectores españoles?

M.V.LL.: La censura no funcionaba así y no le daba al autor la posibilidad de discutir con nadie. Lo comprobé con los cuentos de mi primer libro, Los jefes. Recuerdo muy bien el procedimiento: había que llevar el manuscrito y depositarlo en una ventanita misteriosa de un edificio no menos misterioso en el centro de Madrid. Le daban a uno un papelito con un número, y una fecha en la que tenía que volver. Cuando uno regresaba le devolvían el manuscrito con unas tachaduras hechas a mano que uno tenía que aceptar o, simplemente, el libro no se publicaba. Recuerdo mucho la sorpresa que mi amigo Juan Marsé se llevó cuando, al devolverle un manuscrito censurado, advirtió que el censor había eliminado en el texto todas las veces que aparecía la palabra "sobaco".

M.Á.V.y C.S.T.: ¿Tuvo elección o la editorial tomó esa decisión por usted?

M.V.LL.: Las decisiones siempre las tomé yo y la editorial las respetó. Tengo que decir que la censura solo se mostró intolerante con mis dos primeros libros. Luego nunca volví a tener problemas de censura en España. Sí, en cambio, en otros países como la URSS, donde La ciudad y los perros fue amputada, según un amigo español que hablaba ruso, nada menos que de cuarenta páginas. 


\section{M.Á.V.y C.S.T.:¿Habría afrontado esa situación de la misma forma en la actualidad?}

M.V.LL.: Sí, en la actualidad sigo rechazando la censura como una violación flagrante de la libertad de creación.

M.Á.V. y C.S.T.: En qué medida conserva una obra su valor literario si no se respeta la voluntad de quien la escribe? ¿En qué grado cree que la censura afectó al resultado de sus primeras novelas y a su difusión?

M.V.LL.: La censura crea una gran desconfianza, y no solo en el público que sabe que los libros han sido acomodados de acuerdo a la moral vigente, sino también en los propios autores que a la hora de escribir pierden la espontaneidad y escriben o tratando de evitarla o provocando a la propia censura.

M.Á.V. y C.S.T.: Desde el final de la dictadura, ¿ha valorado la posibilidad de reeditar sus obras de forma integra, sin las supresiones o modificaciones de la censura? ¿Por qué?

M.V.LL.: Todos mis libros, incluidos los dos primeros que pasaron por la censura, se han publicado luego en ediciones íntegras.

\section{Entrevista a José María Vaz de Soto}

José María Vaz de Soto (Paymogo, Huelva, 1938) es catedrático de Lengua y Literatura y novelista, además de colaborador habitual en la prensa española y miembro numerario de la Real Academia Sevillana de Buenas Letras. A pesar de las tachaduras impuestas por la censura, inició su carrera literaria en los años setenta con su primera novela, El infierno y la brisa (1971), que después contó con una adaptación cinematográfica ( Arriba Hazaña!, 1978). Vaz de Soto ha publicado más de una docena de obras, muchas de ellas adscritas al género negro y policial, entre las que se encuentran títulos como Sindrome de Oslo (1998), Perros aborcados (2000) y Memorias de un homicida (2013), su última publicación. Además, es autor de una tetralogía de novelas dialogadas -Diálogos del anochecer (1972), El precursor (1975), Fabián y Sabas (1982) y Diálogos de la alta noche (1982)-, del volumen de relatos titulado En esta ciudad (1990) y del ensayo Defensa del habla andaluza (1981).

María Álvarez Villalobos y Cristina Suárez Toledano:Durante la redacción de sus primeras obras, cuando tomaba una decisión sobre temática, de léxico..., ¿hasta qué punto tenía presente que los textos que estaba escribiendo serian sometidos a la inspección de la censura?

José María Vaz de Soto: Tenía conciencia, sobre todo en los últimos años sesenta, al escribir El infierno y la brisa, del contexto social en que me movía, aunque sin conocer cuáles eran exactamente sus límites. Fue la editorial, Edhasa, la que presentó esta novela a Censura y tardó bastante -a fines de 1970 - en ser autorizada con algunos pequeños cortes.

M.Á.V. y C.S.T.: Cree que la publicación de sus primeras obras pudo verse favorecida o perjudicada por las relaciones de las editoriales Edhasa y Planeta con la administración censora? ¿Cree que ello afectaba de algún modo a su relación con los editores de la época?

J.M.V.S.: Los editores de Edhasa en 1969 y 1970 -Rosa Regàs y otros profesionales procedentes del equipo de Carlos Barral en Seix-Barral- no creo que gozaran de un trato favorable por parte de la Administración franquista de la época, y el cambio ministerial ocurrido mientras la novela estaba en manos de los censores Fraga Iribarne fue sustituido por un ministro del Opus- tampoco creo que favoreciera la autorización de mi novela, de modo que las mínimas tachaduras que sufrió el manuscrito fueron acogidas por mí con alivio.

M.Á.V. y C.S.T.:Tras recibir un informe de denegación o de tachaduras para la publicación de alguna de sus obras, ¿qué camino a seguir le pareció más apropiado: sustituir o suprimir los pasajes tachados o tratar de publicarla de forma integra en el extranjero, con la consecuente pérdida de lectores españoles?

J.M.V.S.: No hubo en mi caso un rechazo total de esa primera novela, y las tachaduras que sufrió fueron, como digo, muy pocas. Mis dos siguientes novelas, Diálogos del anochecer (1972) y El precursor (1975), publicadas por Planeta, ya no se presentaron a la llamada consulta voluntaria. Así que no sufrieron otra censura que la de la propia editorial -más la "autocensura” que yo mismo me apliqué- y fue con la editorial 
Planeta con la que, por así decirlo, negocié algunos puntos. Es posible que el señor Lara Hernández gozara de un trato relativamente favorable por parte de los censores, pero yo lo ignoro.

M.Á.V.y C.S.T.: ¿Tuvo elección o la editorial tomó esa decisión por usted?

J.M.V.S.: Todo lo decidieron las editoriales sin consultarme. Yo no intervine para nada ni tuve jamás en mis manos ningún informe de la Administración.

M.Á.V. y C.S.T.: ¿Habría afrontado esa situación de la misma forma en la actualidad?

J.M.V.S.: En la actualidad no hay censura, o por lo menos no creo que nadie meta para nada la mano en mis novelas, y desde luego, de ser consultado, yo no lo aceptaría.

M.Á.V.y C.S.T.:¿En qué medida cree que conserva una obra su valor literario si no se respeta la voluntad de quien la escribe? ¿En qué grado considera que la censura afectó al resultado de sus primeras novelas y a su difusión?

J.M.V.S.: Depende de cada caso. El valor literario, por lo general, pierde siempre con los cortes, por mínimos que sean. En mi caso, aunque parezca en contradicción con lo dicho hasta aquí, la censura me afectó mucho a la hora de escribir y más todavía a la de leer. Pero tengo que reconocer que, una vez escritas mis novelas, logré publicarlas casi exactamente como las había escrito.

M.Á.V. y C.S.T.:Desde el final de la dictadura, ¿ha valorado la posibilidad de reeditar sus obras de forma integra, sin las supresiones o modificaciones de la censura? ¿Por qué?

J.M.V.S.: Lo he hecho con Diálogos del anochecer, reeditada sin cortes por la editorial Renacimiento, de Sevilla, en 2008. También en El infierno y la brisa, reeditada cuatro o cinco veces por distintas editoriales, he recuperado las frases tachadas en su día por los censores (todo lo tachado puede leerse hoy en la última edición de la editorial Algaida). A partir de esas tres primeras novelas, he escrito y publicado diez novelas más -algunas de ellas escritas todavía durante el régimen franquista- sin atender para nada a la censura, pensando que más pronto o más tarde serían publicadas en libertad. Y acerté.

\section{BY-NC-SA}

